\title{
Ideas for supporting student-centered stem learning through remote labs: a response
}

\author{
Richard E. West ${ }^{1}$ (D) $\cdot$ Rebecca Sansom ${ }^{1} \cdot$ Jennifer Nielson ${ }^{1} \cdot$ Geoff Wright $^{1}$. \\ R. Steven Turley ${ }^{1} \cdot$ Jamie Jensen $^{1} \cdot$ Michael Johnson $^{1}$
}

Accepted: 17 November 2020 / Published online: 25 November 2020

(c) Association for Educational Communications and Technology 2020

\begin{abstract}
This paper is in response to the article entitled "Identifying potential types of guidance for supporting student inquiry when using virtual and remote labs in science: a literature review" by Zacharia et al. (2015). In their review, Zacharia et al. (2015) adopted de Jong and Lazondo's (2014) framework of five inquiry phases for online labs: orientation, conceptualization, investigation, conclusion, and discussion. Zacharia et al. reviewed the literature on Computer-supported Inquiry Learning (CoSIL), and identified best practices for each phase. They concluded, for example, that the orientation/conclusion/discussion phases received the least amount of guidance, while there were many more tools and strategies for providing guidance in the conceptualization/investigation phases. In this paper, we adopt the same inquiry framework as Zacharia et al. (2015) and report strategies that we learned from STEM faculty about how they supported and guided virtual student lab-based learning in these five phases during the recent COVID-19 shutdown. While Zacharia et al. identified tools and processes for enabling all five inquiry phases, add additional practical examples of faculty implementing these phases online as part of COVID-19 emergency remote teaching, and we provide insights for extending the 5-phase framework for future research.
\end{abstract}

Keywords Lab-based learning · Studio-based learning · Virtual labs · Virtual studios · Inquiry-based learning

\section{Introduction}

The COVID-19 pandemic of 2020 was exceptionally disruptive for many industries around the world. In education, there has been a varying level of readiness to adapt to emergency remote teaching (ERT). Some instructors, schools, and disciplines had been developing online learning materials previously and were quick to adapt. However, the transition has

Response to this original paper: https://link.springer.com/article/10.1007/s11423-015-9370-0.

Richard E. West

rickwest@byu.edu

1 Brigham Young University, Provo, UT, USA 
been much more difficult for others, particularly those disciplines that rely on hands-on, active learning approaches-including STEM disciplines.

In these disciplines, there has been an increased emphasis on adopting student-centered, evidence-based learning practices, only to have the transition complicated by COVID19. Code et al. (2020) surveyed teachers in technology education about their main concerns, and reported, 'the switch to ERT impacted the teachers' ability to support handson competency development owing to inequitable student access to tools, materials and resources." Solving this puzzle of how to provide active learning online is a critical concern, as Zayapragassarazan (2020) argued "online education can be effective only if it promotes active learning in learners by providing opportunities to read, write, discuss, think, ask questions, solve problems, analyze and create new things depending on the learning content" (p. 1).

One area of concern especially in the STEM disciplines is with lab-based learning. Ray and Srivastava (2020) acknowledged that virtual labs can be a helpful supplement to inperson labs, but they wondered "whether virtual labs can completely replace the real-life physical labs" (p. 79). To answer this question, we need effective frameworks for researching and understanding virtual lab-based learning. In their review, Zacharia et al. (2015) adopted de Jong et al.'s (2014) framework of five inquiry phases for online labs: orientation, conceptualization, investigation, conclusion, and discussion. Zacharia et al. reviewed the literature on Computer-supported Inquiry Learning (CoSIL), in order to determine whether research and practice have developed sufficiently to support inquiry-based learning online. They found that there do exist tools and strategies to support each phase, but that some phases have received more attention than others. They concluded, for example, that the orientation/conclusion/discussion phases received the least amount of attention in the CoSIL literature, while there were many more tools and strategies for providing guidance in the conceptualization/investigation phases. They concluded with a call for more research into how faculty implement these inquiry phases online, and also how to train and support faculty in these efforts.

In our response to Zacharia et al.'s paper, we seek to address, briefly, these areas while also sharing our insights into how to extend and further develop the 5-phase framework. At our university, we created the STEM Faculty Institute, funded by a grant from the National Science Foundation, to support and train STEM faculty in student-centered teaching. When the COVID-19 pandemic hit, we pivoted our professional development support to focus on online learning. In this paper, we adopt the same inquiry framework as Zacharia et al. (2015) and report strategies that our STEMFI participants and workshop presenters shared about how they guided virtual student lab-based learning in these five phases during the COVID-19 pandemic and shift to online teaching.

\section{STEMFI faculty strategies}

\section{Orientation and conceptualization strategies}

The instructors we talked to reported orienting students online mostly in the same way they did it in person. For example, they might use the same handouts to explain the inquiry project. Instead of synchronous in-person class meetings, they often used synchronous video class sessions to orient students to the project and to teach background concepts. Another 
strategy reported was to record an introductory video explaining the lab activity that student teams could view asynchronously within their video break-out rooms.

Instructors also recorded themselves, or had their teaching assistants record themselves, demonstrating the lab procedures. While this has some limitations, as students cannot easily ask questions while the instructor demonstrates the process, video demonstrations can allow students to slow down or repeat forgotten steps.

One member of our team utilized video demonstrations for another purpose - to facilitate student self-directed learning and enable more personalized mentoring. In his course on educational technology strategies, there were several lab-based projects utilizing technologies the students had available at home. By recording process and introduction videos, most students were able to successfully learn the skills on their own, which was more efficient for them and strengthened their ability to self-teach in the future. Those students who needed extra assistance came to on-campus lab sessions for personalized, small-group or one-on-one mentoring. While this strategy began before COVID, it could continue to be useful in situations where campus visits are possible in small, instead of large, groups.

\section{Investigation strategies}

The investigation phase of lab inquiry is perhaps where there is the greatest opportunity for divergent strategies and creative solutions. One chemistry instructor, teaching a required course for mostly life science and engineering majors, requires her students to purchase athome kits with lab supplies. With synchronous video class sessions to introduce the labs, students can complete the experiments at home.

This provides several positive results. First, students now own some basic lab materials, which could be beneficial for future learning. Second, it allows students to continue their lab-based learning online and anywhere in the world. There are several disadvantages, as well. The at-home labs are significantly more expensive for the students (\$240/person) than an on-campus lab fee. In addition, the quality is entry-level, rather than professionalmeaning that some experiments cannot be completed with the at-home kits, leaving some concerns about whether student learning at home is equivalent. In addition, the instructor believes students are not learning social "process" skills as effectively such as teamwork and group problem-solving. However, continued integration of video communication technologies is helping to alleviate this challenge. Finally, a major disadvantage is one of equity, in that requiring an expensive at-home kit, and additionally requiring synchronous lab sessions with teammates can present significant barriers for students with low financial resources, poor internet, or difficult time zone differences.

Similarly, professors in technology and engineering education created "materials and supplies kits" for students to complete projects at home. Some of the kits provided strong educational experiences such as the robotics unit, where students programmed microcontrollers using nano arduinos. However, other kits were less helpful, such as manufacturing, composites, metals, and furniture design. Although material such as carbon fiber and bonding agents were provided, students were either reluctant to use the materials at home, or did not feel the experience was as authentic. The issue of authenticity especially rang true in the furniture design and metals classes where students were also asked to watch a series of videos that explained the techniques the students would have used had they had access to the various large scale machines and tools. Ultimately, online demos, supplementary videos, and being available online did not provide sufficient educational learning opportunities for the students to adequately learn the material. 
Another potential solution for investigation phases is to use virtual lab simulations. Our university for many years has been using Virtual Chemlab (VCL) for some lab experiments (Woodfield et al. 2004). Typically, the simulation is used to prepare students during the conceptualization phase to do the investigation phase in person. However, during the COVID shutdown, this strategy shifted. One instructor switched to using VCL exclusively, and described that when creatively designed, it can allow students to perform investigations they could never do in person (because they are too dangerous or expensive in a live lab). In some cases, the simulation helps students to see aspects of the experiment they might miss in person, such as the full spectrum of color. However, a strong disadvantage is that many virtual labs are just not as exciting as they would be in person.

Finally, one engineering professor used video tutorials to help scaffold investigation process skills for students. In the video he mimics what the student should be doing, students watch the video in their groups in breakout rooms in Zoom and pause it when given prompts to discuss concepts, decide which valve to open, and judge which data appearing on the instrument is important and should be collected. Using free Open Broadcast Software, the professor created a recording with multiple screens potentially showing his face, video of his lab as he completed steps, his slide presentation, and iPad whiteboard notes at the same time.

\section{Conclusion strategies}

The instructors we talked to said that interpreting the data and drawing conclusions was vastly different in online labs because you can "see" different things in video or simulations than you could in person. For example, without spectrometers, $\mathrm{pH}$ meters, analytical balances, temperature and pressure sensors, etc., there are chemical phenomena that cannot be observed online. As Bernhardt (2018) argued, "when the experimental tools used don't allow for direct observation, students cannot access the phenomena to interpret data and draw conclusions." One useful strategy during this stage was to ask students to complete the lab synchronously in Zoom breakout rooms, so that teaching assistants could rotate into the groups, answer questions, and observe their process skills.

\section{Discussion strategies}

Finally, our teachers used typical synchronous and asynchronous discussion strategies to enable student reflection and discussion after the labs. One difference is that, at least for one instructor, as they used Zoom for office hours, they found they typically worked individually with students to complete their labs instead of in groups as they would do during an in-person lab. We also found that some discussions benefited from using asynchronous video, enabling more social presence and connection while maintaining flexibility for when the conversation occurred (Lowenthal, et al. 2020).

\section{Conclusions}

Overall, we found the framework from Zacharia et al. useful for understanding different strategies that instructors use for online, inquiry-based laboratory learning. Based on our interviews and experiences, we echo their conclusions. First, technology can provide a reasonable at-home and online solution for many courses, but as instructional designers 
we should be sensitive that the online solution may not always be ideal for every course. In many situations, there are tools, instruments, and materials available at in-person laboratories that cannot be fully replicated virtually. However, creative design may improve the future of virtual lab-based learning by creating more authentic simulations (perhaps through augmented or mixed-reality technologies), or through hybrid/blended options where students complete some labs at home but others at school or through partner laboratories if the students live away from the university. Future research and development in this area is critical to understanding how to support each of the five inquiry phases. If not, the "shift to digital" learning risks being a shift to teacher-centered instruction, if we cannot develop the tools to support student-centered lab work effectively.

Second, the framework from Zacharia et al. and de Jong and Lazondo provided a basic summary of the inquiry process, but we realized it may need to be updated. For example, we believe it would be helpful to include a dimension of equity or access, where scholars can parse the literature and create research designs that investigate the positive and negative effect of various online labs on student equity and multicultural learning.

Finally, the framework discusses phases in the lab-based learning process, but is still very broad. Additional refinement may identify different aspects of each phase that should be studied. For example, during the investigation phase, we found that it was not sufficient to think about how technology made investigation possible, but how it made it different. For example, a virtual lab may reproduce some aspects of an experiment with even better visibility than an in-person lab, while diminishing other aspects. It might be that through blending of online and in-person lab learning, and skilled design of learning environments that take advantage of the affordances of each, we can take advantage of both modalities and better prepare students to become the next generation of scientists and engineers.

Funding This work was supported in part by the National Science Foundation under Grant DUE-1712056. Any opinions, findings, and conclusions or recommendations expressed in this material are those of the authors and do not necessarily reflect the views of the National Science Foundation.

\section{References}

Bernhardt, J. (2018). What matters for students' learning in the laboratory? Do not neglect the role of experimental equipment! IInstructional Science, 46, 819-846. https://doi.org/10.1007/s11251-018-9469-x.

Code, J., Ralph, R., \& Forde, K. (2020). Pandemic designs for the future: Perspectives of technology education teachers during COVID-19. Information and Learning Sciences. https://doi.org/10.1108/ ILS-04-2020-0112.

de Jong, T., \& Lazonder, A. W. (2014). The guided discovery principle in multimedia learning. In R. E. Mayer (Ed.), The Cambridge handbook of multimedia learning (2nd ed., pp. 371-390). Cambridge: Cambridge University Press.

de Jong, T., Sotiriou, S., \& Gillet, D. (2014). Innovations in STEM education: The Go-Lab federation of online labs. Smart Learning Environments, 1, 3. https://doi.org/10.1186/s40561-014-0003-6.

Lowenthal, P., Borup, J., West, R., \& Archambault, L. (2020). Thinking Beyond Zoom: Using asynchronous video to maintain connection and engagement during the COVID-19 Pandemic. Journal of Technology and Teacher Education, 28(2), 383-391.

Ray, S., \& Srivastava, S. (2020). Virtualization of science education: A lesson from the COVID-19 pandemic. Journal of Proteins and Proteomics. https://doi.org/10.1007/s42485-020-00038-7.

Woodfield, B. F., Catlin, H. R., Waddoups, G. L., Moore, M. S., Swan, R., Allen, R., \& Bodily, G. (2004). The virtual ChemLab project: A realistic and sophisticated simulation of inorganic qualitative analysis. Journal of Chemical Education, 81(11), 1672.

Zacharia, Z. C., Manoli, C., Xenofontos, N., De Jong, T., Pedaste, M., van Riesen, S. A., ... \& Tsourlidaki, E. (2015). Identifying potential types of guidance for supporting student inquiry when using virtual 
and remote labs in science: A literature review. Educational Technology Research and Development, 63(2), 257-302.

Zayapragassarazan, Z. (2020). COVID-19: Strategies for engaging remote learners in medical education. Online Submission, 9(273), 1-18.

Publisher's Note Springer Nature remains neutral with regard to jurisdictional claims in published maps and institutional affiliations.

Richard E. West (@richardewest on twitter) is an associate professor in the Instructional Psychology and Technology department at Brigham Young University. He teaches courses in instructional technology, academic research and writing, creativity and innovation, design psychology, and product/program evaluation. He has published on how to create learning environments that prepare students for the twenty-first century, including designing learning environments that foster group creativity through design thinking, utilizing microcredentials and open badges to promote competency learning, the development and support of online learning communities, and emerging technologies to support effective learning.

Rebecca L. Sansom is an associate professor in the Chemistry and Biochemistry department at Brigham Young University. She teaches general chemistry, general chemistry laboratory, and chemistry for pre-service teachers. She studies STEM faculty change, learning in laboratory settings, and pedagogies that support the success of all students in university STEM coursework.

Jennifer B. Nielson is a chemistry teaching professor and an associate dean in the College of Physical and Mathematical Sciences at Brigham Young University. Her research is on student engagement in learning science, on recruiting students as secondary STEM teachers, and on effective professional development of STEM educators in the U.S. and in Africa.

Geoffrey A. Wright is an associate professor in the College of Engineering at Brigham Young University. His is currently the program chair of Technology and Engineering Studies. His areas of research and teaching focus on teacher education, specifically engineering and technology education, innovation engineering, mathematical self-efficacy through coding and design, and innovation assessment.

R. Steven Turley is a professor in the Department of Physics and Astronomy at Brigham Young University. He teaches courses in conceptual physical science, modern physics, computational physics, electromagnetic theory, and quantum mechanics. He has published on extreme ultraviolet optics, liberal arts education, teaching numerical literacy, acoustic scattering, computational electromagnetics, $\mathrm{x}$-ray photoelectron spectroscopy, multilayer mirror design, Raman spectroscopy, laser plasma diagnostics, nuclear physics, nonlinear optics, and teaching scientific writing.

Jamie L. Jensen is an associate professor in the Biology Department at Brigham Young University. She teaches introductory biology for majors and non-majors as well as graduate-level pedagogy classes. She studies STEMF faculty change, evidence-based teaching practices in biology education, and the reconciliation of science and religion.

Michael C. Johnson (@michaelcjohnson on twitter) is a teaching \& learning and academic technology consultant at Brigham Young University's Center for Teaching \& Learning. He teaches courses in effective study \& learning strategies and effective university course design. He has published on character development in higher education, blended learning models, effective teaching strategies, and using technologies to support effective learning. 